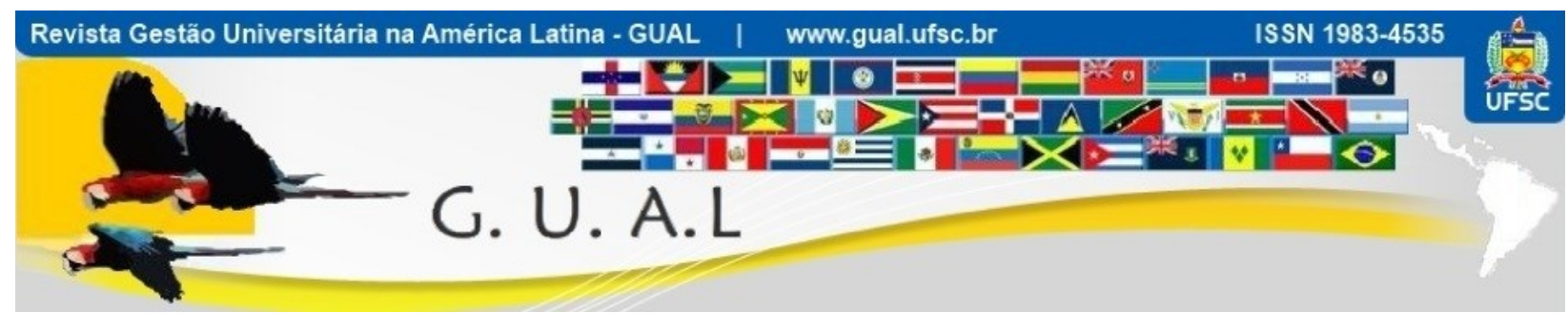

DOI: http://dx.doi.org/10.5007/1983-4535.2017v10n4p47

\title{
BARREIRAS E FACILITADORES NA GESTÃO DE PROCESSOS DE TRABALHO EM INSTITUIÇÃO FEDERAL DE ENSINO SUPERIOR
}

\section{BARRIERS AND FACILITATORS IN PROCESS MANAGEMENT OF A FEDERAL UNIVERSITY}

Marlon Bruno Matos Paiva, Doutorando Universidade Federal do Ceará - UFC mbrunokun@gmail.com

Pedro Paulo Barbosa Feitosa, Graduado Universidade Federal do Ceará - UFC caceres_rs@yahoo.com.br

Augusto Cezar de Aquino Cabral, Doutor Universidade Federal do Ceará - UFC cabral@ufc.br

Sandra Maria dos Santos, Doutora Universidade Federal do Ceará $\underline{\text { smsantos@ufc.br }}$

Recebido em 25/novembro/2016

Aprovado em 16/outubro/2017

Sistema de Avaliação: Double Blind Review

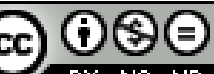

Esta obra está sob uma Licença Creative Commons Atribuição-Uso. 


\title{
RESUMO
}

O objetivo principal desta pesquisa foi analisar os fatores que interferem na gestão de processos de trabalho em uma Instituição Federal de Ensino Superior. A pesquisa, quantitativa, analisou dados coletados por meio de survey aplicada a servidores técnicoadministrativos da Universidade Federal do Ceará, com uma amostra composta por 78 indivíduos. Os resultados confirmaram as hipóteses relativas aos benefícios e facilitadores à gestão de processos. Foi rejeitada a hipótese relativa às barreiras, tendo em vista que os servidores aparentam ser indiferentes quando às dificuldades apresentadas na pesquisa. Verifica-se que a gestão de processos é vista como uma intervenção positiva na administração pública e que há receptividade dos servidores a fim de que a desburocratização possa tornarse rotina de gestão, atendendo de forma satisfatória os clientes das instituições.

Palavras chave: Gestão de processos. Desburocratização. Universidade.

\begin{abstract}
The aim of this research was analyzing which factors interfere in process management of a Federal University. The quantitative research analyzed data collected through a survey applied to a sample of 78 workers from Federal University of Ceará (UFC). The results confirmed all hypotheses related to benefits and facilitators of the process management. The hypothesis about barriers was rejected given to the federal workers appear to be indifferent to the difficulties presented in this research. We conclude that process management is seen as a positive intervention to public administration and there is receptivity from workers in order to debureaucratization can become management routine, satisfying costumers from public institutions.
\end{abstract}

Keywords: Process Management, Debureaucratization, University. 


\section{INTRODUÇÃO}

O início desde século foi marcado por mudanças nas organizações. Elas reestruturaram os processos de trabalho, o tipo de recursos humanos necessários, a forma de tratamento e disseminação das informações, alavancados principalmente pelo uso de tecnologias computacionais para realização de suas atividades. A organização pública não ficou isenta deste processo, apesar de seu atraso tecnológico. As organizações públicas procuram alcançar a modernização dos serviços, através de sérias modificações, que influenciam no oferecimento de serviços e na forma como ela é encarada pela população, que exige atendimento com qualidade e agilidade (TAIT, 2000).

A realidade brasileira aponta para o despreparo com que é tratada a qualidade do serviço público, em todas suas dimensões. As teorias administrativas parecem não andar lado a lado com os gestores, fazendo com que a máquina pública se desvie de seus reais objetivos, comprometendo os resultados que deveriam refletir, positivamente, na sociedade (SILVA; PERIOTTO, 2007).

Nesse contexto, a gestão por processos surge como uma metodologia consolidada tanto na iniciativa privada como nas organizações públicas, a fim de alcançar melhores resultados através do aperfeiçoamento dos processos de trabalho. Nesse modelo, todos os servidores desempenham ações de forma contínua, que envolvem conhecer, analisar, mudar e monitorar as rotinas de trabalho (MPF/PGR, 2013).

Apresenta-se processo como um conjunto integrado e sincrônico de insumos, infraestruturas, regras e transformações, que adiciona valor às pessoas que fazem uso dos produtos e/ou serviços gerados. Essa visão reforça a ideia de que processos possuem o compromisso de satisfazer as necessidades dos clientes, no caso do serviço público, os cidadãos (MPOG, 2011).

Para Paim et al (2009), a gestão de processos trata de um conjunto articulado de tarefas permanentes para projetar e promover o funcionamento e o aprendizado da organização no que diz respeito a seus processos de trabalho. Dessa forma, a gestão de processos é vista como um modelo de gestão que possui ferramentas para modernizar e melhorar a qualidade do serviço prestado ao cidadão.

A maioria das Instituições Federais de Ensino Superior (IFES) passam por dificuldades pelo fato de estarem vinculadas às imposições burocráticas na legislação brasileira (LORENA, 2015). De acordo com Oliveira, Kamimura e Tadeucci (2011), por mais 
que o ambiente universitário seja visto como um local de desenvolvimento de inovações e geração de conhecimentos, não se observa o mesmo para os processos administrativos e decisórios.

Dessa forma, tais organizações necessitam buscar um modelo de gestão que viabilize uma atuação gerencial facilitadora de processos organizacionais, tornando-se mais ágeis e acompanhando o ritmo das mudanças sociais (LORENA, 2015).

Diante do exposto, este estudo pretende responder o seguinte questionamento: que fatores interferem na gestão de processos de trabalho em uma Instituição Federal de Ensino Superior?

$\mathrm{Na}$ busca de respostas para o problema central da pesquisa, o objetivo geral é analisar os fatores que interferem na gestão de processos de trabalho em uma Instituição Federal de Ensino Superior. Foram formulados os seguintes objetivos específicos:

1. Analisar os benefícios percebidos pela gestão de processos de trabalho;

2. Analisar as barreiras para a gestão de processos de trabalho;

3. Analisar os facilitadores para a gestão de processos de trabalho.

Foram elaboradas as seguintes hipóteses relacionadas a cada um dos objetivos específicos da pesquisa:

1. O uso dos manuais de procedimentos garante melhor desempenho e eficiência no trabalho realizado, com foco no cliente;

2. As barreiras existentes na gestão de processos dificultam o uso dos manuais de procedimentos pelos servidores da instituição;

3. Com as informações e ferramentas adequadas, os servidores passam a utilizar mais os manuais de procedimentos, melhorando a gestão de processos.

O estudo se justifica por poder contribuir para melhorias nas relações de trabalho e no desempenho da instituição pública através de um melhor conhecimento do perfil dos servidores, ajudando a levantar informações sobre a realidade das Instituições Federais de Ensino Superior que, como fontes geradoras do conhecimento, devem estar contextualizadas em relação às mudanças organizacionais. Isto poderá proporcionar políticas de gestão adequadas, buscando garantir a evolução e profissionalização da administração pública.

Várias iniciativas conduzidas no Governo relacionadas à gestão de processos de trabalho carecem de integração, dificultando ou impossibilitando o compartilhamento de resultados nos moldes de cadeias de valor intra e entre instituições. Isto traz consequências 
para a execução com sucesso de iniciativas como a simplificação do atendimento ao cidadão e o alinhamento da visão de processos à de dados (MPOG, 2011).

Desde 2005, com a criação do Programa Nacional de Gestão Pública e Desburocratização (GESPÚBLICA), o governo federal brasileiro ratifica a necessidade de ações de melhoria na qualidade dos serviços públicos prestados aos cidadãos e aumento da competitividade do país. Nesse sentido, uma das vertentes de ações adotadas tem sido a melhoria dos processos e normas, através da simplificação dos mesmos. Salienta-se que, além do desenvolvimento dessas ações nas diferentes instituições públicas, espera-se que o conhecimento seja multiplicado e que os servidores sejam capacitados (MPOG, 2006).

Isso corrobora para a necessidade da padronização de processos e uso de manuais de procedimentos que, conforme Oliveira (2005), descreve os papéis desempenhados pelos diferentes departamentos e padroniza os procedimentos envolvidos na execução de tarefas, possibilitando adequação, coerência e continuidade nas atividades, com efetivo crescimento na eficiência e eficácia dos trabalhos, aprimorando os sistemas de autoridade da instituição e aumentando a predisposição do pessoal em assumir responsabilidades.

Para fins metodológicos, realiza-se uma pesquisa analítica de natureza quantitativa, através da análise de dados primários coletados por meio de survey aplicada a servidores técnico-administrativos da Universidade Federal do Ceará.

O artigo está estruturado em cinco tópicos, incluindo esta introdução. A seguir, apresenta-se a revisão da literatura, tratando da conceituação de gestão de processos e manuais de procedimentos na administração pública. Na metodologia são apresentados o enquadramento metodológico e os procedimentos para coleta e análise dos dados, sendo seguida pelos resultados da pesquisa. No último tópico, apresentam-se as considerações finais do estudo.

\section{REFERENCIAL TEÓRICO}

Nessa seção serão abordados os temas gestão de processos e desburocratização do serviço público para a descrição e análise do fenômeno pesquisado. Também são apresentados estudos empíricos anteriores acerca da temática estudada.

\subsection{GESTÃO DE PROCESSOS}

Processo é qualquer atividade ou conjunto de atividades que toma um input, adiciona valor a ele e fornece um output a um cliente específico. Olhando de outra maneira, os 
processos de trabalho são atividades coordenadas que envolvem pessoas, procedimentos e tecnologia (GONÇALVES, 2000). Para o autor, processo de trabalho pode ainda ser definido como qualquer trabalho que seja recorrente, afete algum aspecto da capacitação da organização, podendo ser realizado de maneiras distintas e com resultados diferentes em termos da contribuição que pode gerar, seja em relação a custo, valor, serviço ou qualidade, envolvendo a coordenação de esforços para a sua realização.

A Gestão de Processos de Negócio (BPM), surgiu no início do da década de 90 após o crescimento do interesse na Gestão de Processos de Reengenharia (BPR). As lições dos casos de sucesso e de fracasso de implementação nessa área mostram que a abordagem revolucionária da reengenharia foi sendo suavizada, o que possibilitou o nascimento e o crescimento das pesquisas em Gestão de Processos de Negócio (MELÃO; PIDD, 2000). É importante comentar que o BPR busca uma mudança revolucionária nos processos de trabalho, produzindo uma ruptura completa entre o antes e o depois da intervenção. Já o seu descendente BPM atua de forma mais prática, incremental e contínua. (AALST; HOFSTEDE; WESKE, 2003)

De acordo com Luo e Tung (1999) uma organização pode ser vista como uma série de processos interrelacionados desenhados com o objetivo de atender as metas organizacionais estabelecidas. Segundo o Guia para o Gerenciamento de Processos de Negócio - Corpo Comum de Conhecimento (BPM CBOK):

Gerenciamento de Processos de Negócio (BPM - Business Process Management) é uma disciplina gerencial que integra estratégias e objetivos de uma organização com expectativas e necessidades de clientes, por meio do foco em processos ponta a ponta. BPM engloba estratégias, objetivos, cultura, estruturas organizacionais, papeis, políticas, métodos e tecnologias para analisar, desenhar, implementar, gerenciar desempenho, transformar e estabelecer a governança de processos (ABPMP, 2013).

A adoção de BPM requer a difusão de sua importância e o estabelecimento de um conjunto de serviços e metodologias, ferramentas e técnicas fundamentais no ciclo de vida da gestão de processos. Inicia-se com a modelagem, análise e redesenho de processos, passando em seguida para uma mudança no modo a qual uma organização executa e melhora suas operações (ROSEMANN et al, 2009).

Se as organizações são compostas por processos, faz todo sentido analisá-las através da ótica da gestão de processos. Isso valida o uso do BPM nas organizações, pois essa 
ferramenta trata de direcionar e orientar as instituições e suas ferramentas de gestão, reduzindo a sua dependência em estruturas funcionais e territoriais (ABPMP, 2013).

Mas por que é importante reduzir a dependência das organizações das estruturas funcionais? Segundo Lizarelli et al (2006), ao priorizar as funções de cada departamento da empresa, em detrimento dos processos essenciais, as empresas executam pedaços fragmentados dos processos de trabalho. Para corrigir esses problemas o autor afirma que a gestão por processos organizacionais possui, pelo menos, três pontos de clara divergência das funções tradicionais: empregam objetivos com foco no cliente, os recursos são organizados de forma a produzir um trabalho completo e a informação segue diretamente para onde é necessária.

O investimento que organizações têm realizado em iniciativas de Gestão de Processos de Negócio (Business Process Management - BPM) tem levado a transformações significativas nas mesmas, tais como aumento da eficiência operacional, oferta de novos serviços, automação de processos, melhoria de performance e práticas de conformidade (Rosemann et al, 2009).

Benedictis, Amaral e Rozenfeld (2004) afirmam que a modelagem de processos de negócios possibilita entender como os trabalhos são realizados, considerando o fluxo de atividades e informações da organização, uniformizando o entendimento e os procedimentos de trabalho através da integração, análise e melhoria dos fluxos de informação, além de documentar os processos que integram as diferentes áreas da instituição.

No entanto, o avanço da gestão de processos é parcialmente prejudicado pelo fato de que o BPM, enquanto disciplina, ainda não encontrou um local ou área que a represente, sendo comum que suas iniciativas sejam conduzidas de forma isolada dentro da organização, faltando sinergia e com limitação de retorno sobre os investimentos em BPM. Tais práticas fragmentadas dificultam os esforços, impedindo a consolidação dos benefícios oferecidos pela Gestão de Processos e trazendo baixa credibilidade (ROSEMANN et al, 2009).

Na perspectiva do serviço público, o Ministério do Planejamento, Orçamento e Gestão constatou que as várias iniciativas conduzidas no Governo relacionadas à gestão de processos de negócio carecem de integração, dificultando ou impossibilitando o compartilhamento de resultados nos moldes de cadeias de valor intra e entre instituições (MPOG, 2011).

Dessa forma, é necessária a integração entre gestão estratégica e gestão por processos como condição essencial para o sucesso de ambas as abordagens nas instituições 
governamentais. $\mathrm{O}$ cumprimento das metas definidas é consequência direta da modernização dos processos que passam a atingir um novo nível de desempenho. Uma estratégia somente pode ser bem-sucedida pela transformação dos seus processos organizacionais (MPF/PRG, 2013).

\subsection{DESBUROCRATIZAÇÃO NO SERVIÇO PÚBLICO}

Toda organização desenvolve, no seu cotidiano, inúmeras atividades rotineiras, que levam à produção dos mais variados resultados na forma de produtos e serviços. Tais atividades, devido à sua natureza e à dos resultados gerados, podem ser enquadradas na forma de processos organizacionais que, de forma integrada, trabalham no sentido de promover a consecução dos objetivos principais da organização, diretamente relacionados a sua missão (MPOG, 2006).

Os processos organizacionais geralmente produzem resultados imperceptíveis para os clientes externos, mas são essenciais para a gestão efetiva do negócio. A primeira característica importante dos processos é a interfuncionalidade. Embora alguns processos sejam inteiramente realizados dentro de uma unidade funcional, a maioria dos processos importantes das organizações, especialmente processos de negócio, atravessa as fronteiras das áreas funcionais (GONÇALVES, 2000).

Os gestores e servidores públicos que aceitaram transformar as antigas estruturas burocráticas, o departamentalismo e o corporativismo implantando políticas e metodologias que viabilizem uma administração moderna voltada, que atenda aos interesses dos cidadãos, encontraram uma oportunidade para reavivar as suas convicções e reforçar as suas posições com a era da informação e com o uso das novas tecnologias (COELHO, 2001).

Os elos entre a administração e a ciência da informação, no contexto das organizações, geralmente se encontram encapsulados em diversas discussões, no meio das quais está a gestão por processos. Nesse sentido, encontra-se o desafio de elaborar uma síntese conceitual entre o modelo burocrático e modelos mais gerencialistas que permita a modelagem das organizações do serviço público segundo as necessidades de seus usuários, tendo como condicionantes a evolução social e tecnológica em curso, e a capacidade de por tais ferramentas em prática, tendo em vista os substratos cultural-institucional, político, econômico e sociotécnico vigentes (CAPUANO, 2008). 
O desafio do administrador público é implementar um modelo de gestão que minimize custos, racionalize e elimine entraves, reduza o tempo de resposta às demandas externas e internas dos órgãos, atendendo ainda as expectativas da sociedade (OLIVEIRA NETO, 2004).

De acordo com o Ministério do Planejamento, Orçamento e Gestão (2006), o Programa Nacional de Desburocratização, criado em 1979, explicitou a necessidade do Estado em combater os excessos das exigências formais, muitas vezes, desnecessárias que atrasam ou muitas vezes impedem os cidadãos de receberem serviços e terem seus direitos garantidos. Por esse motivo, foi criado em 2005, o Programa Nacional de Gestão Pública e Desburocratização, que ratificou a necessidade de ações voltadas à desburocratização na busca da melhoria da qualidade dos serviços públicos prestados aos cidadãos e no aumento da competitividade do País (MPOG, 2006).

Homburg (2004) conceitua a Nova Gestão Pública (NPM) como um conjunto de estratégias e táticas que procuram melhorar a capacidade dos órgãos de governo e suas entidades colaboradoras para produzir resultados mediante a reinvenção do governo. $\mathrm{O}$ autor observa que o paradigma tradicional (weberiano) de administração pública tem sido criticado desde os anos 1970 pelo seu desempenho insatisfatório, na prática, e que a intensificação do ressentimento dos cidadãos com o serviço público coincidiu com o desenvolvimento acadêmico de teorias econômicas, como o neoinstitucionalismo, e teorias administrativas ancoradas na ciência política (HOMBURG, 2004; CAPUANO, 2008).

A desburocratização possui dois focos principais. Um deles está voltado à desregulamentação de normas que interferem de maneira exagerada nas relações de direito e obrigações entre Estado e cidadão. O segundo busca a simplificação de processos, procedimentos, rotinas e atividades, a fim de gerar fluxos que agreguem valor ao serviço prestado pelo Estado (MPOG, 2006).

O Decreto $n^{\circ} 6.932 / 2009$, que dispõe sobre a simplificação do atendimento público prestado ao cidadão, apresenta, entre as diretrizes que os órgãos do Poder Executivo Federal devem seguir nas relações com o cidadão, a racionalização de métodos e procedimentos de controle, a eliminação de formalidades cujo custo econômico ou social seja superior ao risco envolvido e a aplicação de soluções tecnológicas que visem a simplificar processos e procedimentos e a propiciar melhores condições para o compartilhamento das informações.

Com a necessidade do fortalecimento da transparência na gestão dos recursos públicos, aumenta a responsabilidade dos gestores em corresponder aos anseios da sociedade 
que clama por mudanças sustentáveis, cumprindo leis e normas, princípios da legalidade, impessoalidade, moralidade, publicidade e eficiência. Ferramentas estas que servem para facilitar a gestão transparente, eficiente e voltada para o interesse público (OLIVEIRA NETO, 2004).

Os processos são um instrumento que permite aproximar diretrizes estratégicas e executores do trabalho nas instituições públicas, permitindo o alcance de objetivos. $\mathrm{O}$ foco no cidadão faz com que o setor público oriente seus processos ao atendimento das necessidades deste agente e os prestadores de serviço do Governo devem ter seus processos modelados, automatizados e geridos, provendo maior controle e qualidade às iniciativas desempenhadas (MPOG, 2011).

No Brasil, um dos problemas de difícil solução é a predominância de uma gestão fundamentada em estruturas com excessivos níveis hierárquicos e departamentos que geram lentidão administrativa, comunicação formal, burocrática, além de serviços e produtos que não satisfazem à população. Contra esse problema, a administração moderna sugere o gerenciamento de processos. Esse enfoque de gestão defende que a organização deve mudar a forma de pensar, abandonar a visão de estrutura departamentalizada e concentrar a atenção nos processos (DANTAS; QUEIROZ; QUEIROZ, 2010).

A gestão por processos surge como uma metodologia consolidada tanto na iniciativa privada como nas organizações públicas, a fim de alcançar melhores resultados através do aperfeiçoamento dos processos de trabalho. Nesse modelo, todos os servidores desempenham ações de forma contínua, que envolvem conhecer, analisar, mudar e monitorar as rotinas de trabalho. Por isso, é necessária a conscientização e a mobilização de todos os envolvidos (MPF/PGR, 2013).

Constatou-se que as várias iniciativas conduzidas no Governo relacionadas à gestão de processos de negócio carecem de integração, dificultando ou impossibilitando o compartilhamento de resultados nos moldes de cadeias de valor intra e entre instituições (MPOG, 2011). Em relação à gestão de processos, uma pesquisa aplicada em Instituição Pública de Nível Superior observou que a existência de questões burocráticas não apenas interfere na agilidade dos processos, como também limitam a imediata aplicação das propostas de melhoria sugeridas. Entretanto, a modelagem de processos de negócio demonstrou-se aplicável como instrumento de gestão e melhoria de processos (MÜCKENBERGER et al, 2013). 
Dessa forma, percebe-se a importância da gestão de processos nas instituições governamentais como fator diferencial para modernização e melhoria do trabalho, com foco nos clientes internos e externos e de uma gestão que atende o princípio da eficiência, uma das premissas do serviço público.

\subsection{ESTUDOS EMPÍRICOS ANTERIORES}

Diante da relevância das temáticas estudadas, diversos estudos com diferentes perspectivas foram desenvolvidos. A Figura 1 destaca alguns destes estudos empíricos.

Figura 1 Estudos empíricos anteriores.

\begin{tabular}{|c|c|c|}
\hline Autor (ano) & Objetivo & Principais resultados \\
\hline $\begin{array}{l}\text { DANTAS; } \\
\text { QUEIROZ; } \\
\text { QUEIROZ } \\
(2010)\end{array}$ & $\begin{array}{l}\text { Descrever e avaliar a gestão de } \\
\text { processos numa unidade de um } \\
\text { órgão público. }\end{array}$ & $\begin{array}{l}\text { Os resultados preliminares permitiram a } \\
\text { identificação e o mapeamento de todas as atividades } \\
\text { da unidade. A análise realizada resultou na } \\
\text { necessidade de atualizar } 48 \% \text { dos processos, o que } \\
\text { foi fundamental para a compreensão das atividades } \\
\text { e a identificação dos pontos de melhoria. }\end{array}$ \\
\hline $\begin{array}{l}\text { SANTOS; } \\
\text { SANTANA; } \\
\text { ALVES } \\
(2012)\end{array}$ & $\begin{array}{l}\text { Analisar a relação existente } \\
\text { entre Fatores Críticos de } \\
\text { Sucesso (FCS) frequentemente } \\
\text { encontrados na literatura e } \\
\text { fatores enfrentados nas } \\
\text { iniciativas de Gestão de } \\
\text { Processos de Negócio } \\
\text { (Business Process Management } \\
\text { - BPM) no Setor Público. }\end{array}$ & $\begin{array}{l}\text { Constataram-se fatores que são singulares ao Setor } \\
\text { Público, demonstrando barreiras e facilitadores além } \\
\text { daqueles encontrados na literatura tais como, } \\
\text { burocracia e cultura do setor público, legislação, } \\
\text { integração entre os órgãos do setor público, } \\
\text { histórico de falhas em projetos de melhorias e } \\
\text { descontinuidade dos projetos por causa da troca de } \\
\text { governo. }\end{array}$ \\
\hline $\begin{array}{l}\text { MÜCKENB } \\
\text { ERGER et } \\
\text { al (2013) }\end{array}$ & $\begin{array}{l}\text { Verificar a aplicabilidade do } \\
\text { gerenciamento de processos de } \\
\text { negócio (BPM) na gestão de } \\
\text { um dos processos mais } \\
\text { fundamentais no processo de } \\
\text { internacionalização de uma IES }\end{array}$ & $\begin{array}{l}\text { Foi possível observar a existência de questões } \\
\text { burocráticas da IES que não apenas interferem na } \\
\text { agilidade do processo de realização de convênios, } \\
\text { como também limitam a imediata aplicação das } \\
\text { propostas de melhoria sugeridas. Entretanto, o BPM } \\
\text { demonstrou-se aplicável como instrumento de } \\
\text { gestão e melhoria de processos. }\end{array}$ \\
\hline $\begin{array}{l}\text { LORENA } \\
(2015)\end{array}$ & $\begin{array}{l}\text { Analisar como as ouvidorias } \\
\text { públicas poderiam auxiliar } \\
\text { estrategicamente a Gestão de } \\
\text { Processos de Negócios ou BPM } \\
\text { (Business Process } \\
\text { Management) nas IFES }\end{array}$ & $\begin{array}{l}\text { A ouvidoria pública pode contribuir para a } \\
\text { implantação e manutenção das práticas de BPM nas } \\
\text { IFES através da geração de informações com base } \\
\text { nas demandas recebidas e identificando } \\
\text { oportunidades de melhoria, ajudando a identificar os } \\
\text { gargalos organizacionais e sugerindo alternativas } \\
\text { para evitar futuros problemas. }\end{array}$ \\
\hline
\end{tabular}

Fonte: Elaborado pelos autores.

A maioria dos estudos realizados no âmbito da gestão de processos tem buscado apresentar a aplicação do modelo em uma unidade de trabalho, verificando a viabilidade do 
método. Este trabalho se diferencia dos demais por analisar os benefícios, barreiras e facilitadores que interferem na gestão de processos de trabalho no serviço público em unidades em que a gestão de processos de trabalho já vem sendo trabalhada.

\section{METODOLOGIA DE PESQUISA}

Quanto à tipologia, esta pesquisa possui caráter analítico, pois, conforme Collis e Hussey (2005), a pesquisa analítica tem como objetivo entender fenômenos, descobrindo e mensurando relações causais entre eles. Busca-se, neste estudo, analisar os fatores que interferem na gestão de processos de trabalho em uma Instituição Federal de Ensino Superior.

Utiliza-se uma abordagem quantitativa, pois, de acordo com Creswell (2010), a pesquisa quantitativa é um meio para testar teorias objetivas, examinando a relação entre as variáveis. Estas variáveis são medidas tipicamente por instrumentos, para que os dados numéricos possam ser estatisticamente analisados.

Uma survey foi empregada como método de coleta de dados. May (2004) afirma que as surveys são um dos métodos empregados com mais frequência na pesquisa social, pois elas oferecem uma maneira rápida e relativamente barata de descobrir as características e crenças de uma população. De forma geral, visam descrever ou explicar as características ou opiniões de uma população através da utilização de uma amostra representativa.

O instrumento de coleta de dados foi composto de um formulário sócio-demográfico de identificação dos respondentes e de questionário elaborado a partir dos conceitos acerca dos benefícios da gestão de processos apresentados por Paim et al (2009) e ABPMP (2013) e ainda das barreiras e facilitadores no sucesso da gestão de processos apresentados por Santos, Santana e Alves (2011).

O questionário conta com vinte e seis questões. As duas primeiras questões tratam do conhecimento e uso dos manuais de procedimentos. Há dezesseis questões acerca dos benefícios da gestão de processos de trabalho e oito questões acerca das barreiras e facilitadores no sucesso da gestão de processos.

As questões acerca dos benefícios da gestão de processos foram divididas em quatro subcategorias, de acordo com os benefícios da gestão de processos elencados na literatura (BENEDICTIS; AMARAL; ROZENFELD,2004; LIZARELLI et al, 2006; PAIM et al (2009); ROSEMANN et al, 2009; AMPMP (2013). A Figura 2 relaciona as afirmações do questionário aos objetivos específicos e às variáveis da pesquisa. 
Figura 2 Relação entre objetivos específicos, variáveis e questões.

\begin{tabular}{|c|c|c|c|}
\hline Objetivo Específico & Subcategoria / Variável & $\begin{array}{l}\text { Número } \\
\text { de Itens }\end{array}$ & Questões \\
\hline \multirow{4}{*}{$\begin{array}{l}\text { 1. Analisar os benefícios } \\
\text { percebidos pela gestão de } \\
\text { processos de trabalho }\end{array}$} & Foco no cliente & 3 & $5,15,16$ \\
\hline & Eficiência operacional & 4 & $4,7,10,11$ \\
\hline & $\begin{array}{l}\text { Melhoria do desempenho } \\
\text { individual }\end{array}$ & 5 & $6,12,13,17,18$ \\
\hline & Fluxo adequado de informações & 4 & $3,8,9,14$ \\
\hline $\begin{array}{l}\text { 2. Analisar as barreiras para a } \\
\text { gestão de processos de } \\
\text { trabalho }\end{array}$ & $\begin{array}{l}\text { Barreiras para a gestão de } \\
\text { processos }\end{array}$ & 5 & $19,20,22,25,26$ \\
\hline $\begin{array}{l}\text { 3. Analisar os facilitadores } \\
\text { para a gestão de processos de } \\
\text { trabalho }\end{array}$ & $\begin{array}{l}\text { Facilitadores para a gestão de } \\
\text { processos }\end{array}$ & 3 & $21,23,24$ \\
\hline
\end{tabular}

Fonte: Elaborado pelos autores.

Segundo o Plano de Desenvolvimento Institucional (PDI) da Universidade Federal do Ceará, entre as metas da UFC, estão a qualificação ampla do efetivo da UFC e a modernização dos instrumentos de gestão, a fimm de alcançar patamares mais elevados de desempenho acadêmico.

Para isso, entre alguns dos objetivos, apresentam-se mapear processos de trabalho e competências individuais e de equipes em uma unidade-piloto e, posteriormente, em todas as unidades da Universidade; ampliar o bem-estar, a satisfação, o comprometimento, a produtividade e a qualidade do trabalho por meio de intervenções concretas nos processos e na estruturação do trabalho, e; maximizar a eficiência, a qualidade e a integridade dos processos e informações de pessoal, para favorecer o controle e a segurança institucionais (UFC, 2012).

Dessa forma, o universo amostral da pesquisa foi composto por servidores técnicoadministrativos da Universidade Federal do Ceará. Foram selecionadas, como unidades de análise, as unidades da UFC que realizaram manualização de processos formalizada na PróReitoria de Planejamento da Universidade: Pró-Reitoria de Administração (PRADM); PróReitoria de Assuntos Estudantis (PRAE); Pró-Reitoria de Gestão de Pessoas (PROGEP); PróReitoria de Planejamento (PRPL); e Superintendência de Infraestrutura (UFC Infra). Dessa forma, o universo amostral foi composto pelos 491 servidores em atividade nessas unidades.

A amostragem da pesquisa foi probabilística e acidental, pois os questionários foram enviados por correio eletrônico (e-mail) via internet a todos os sujeitos da pesquisa. Para a pesquisa, foi determinada uma amostra censitária de devolução voluntária do questionário enviado à referida população dos respondentes. 
O questionário esteve disponível para resposta através de formulário eletrônico no período de 31 de maio de 2016 a 11 de junho de 2016. Dos 491 e-mails enviados, 55 foram devolvidos por falha nos servidores ou registro incorreto nos sistemas de informação. Foi utilizada uma amostra de 78 servidores, que foi o número de questionários válidos retornados.

\section{RESULTADOS}

A amostra, composta de 78 indivíduos, apresentou 49 do sexo feminino (63\%), onde $31(40 \%)$ possuem até 30 anos de idade, 34 (44\%) estão entre 31 e 49 anos e $13(17 \%)$ possuem 50 anos de idade ou mais.

A distribuição da amostra em relação à última titulação completa foi de 54 servidores graduados (69\%) e 21 servidores com título de mestrado (27\%). Apenas 2 servidores possuem nível médio como titulação máxima e 1 servidor possui doutorado.

Em relação ao tempo de serviço na Universidade Federal do Ceará, 30 respondentes possuem menos de 3 anos na instituição (38\%), o que caracteriza que os mesmos ainda se encontram em estágio probatório. 31 servidores possuem entre 3 e 10 anos de serviço $(40 \%)$ e 17 possuem mais de 10 anos de serviço (22\%). A maioria dos servidores em início de carreira se explica pelo grande volume de concursos públicos realizados pela Universidade nos últimos anos e pela autorização do provimento de cargos vagos sem prévia autorização do Ministério do Planejamento, Orçamento e Gestão e do Ministério da Educação, pelo decreto $\mathrm{n}^{\mathrm{o}} 7.232$ de 19 de julho de 2010, automatizando a renovação do quadro de pessoal dos servidores técnico-administrativos.

Antes de analisar os benefícios percebidos pela gestão de processos, verificou-se o conhecimento e uso dos manuais utilizados para a gestão de processos de trabalho nas unidades pesquisadas. 19 respondentes $(24,4 \%)$ afirmaram desconhecer os manuais de procedimentos da sua própria unidade de trabalho, disponíveis no site da Universidade. Do total de participantes da pesquisa, apenas 53 (67,9\%) responderam já terem utilizado, pelo menos uma vez, os manuais de procedimentos da sua unidade de trabalho. Dessa forma, para responder o primeiro objetivo específico da pesquisa, que é analisar os benefícios percebidos pela gestão de processos de trabalho, foram desconsideradas as respostas dos 25 indivíduos que afirmaram nunca ter utilizado os manuais. 
A hipótese 1 previa que o uso dos manuais de procedimento garante melhor desempenho e eficiência no trabalho realizado, com foco no cliente. Para investigar e tais hipóteses, foram empregados procedimentos estatísticos de análise descritiva e inferencial.

Inicialmente, tomou-se a amostra como um todo e analisou-se a concordância atribuída pelos respondentes aos benefícios percebidos pela gestão de processos, tendo como critério a média $(\mathrm{M})$ e o desvio-padrão $(\mathrm{sd})$. O resultado indica uma alta concordância acerca da existência de benefícios ao trabalho em relação à gestão de processos e o uso dos manuais de procedimento $(\mathrm{M}=4,08)$, com forte convergência entre os respondentes $(\mathrm{sd}=0,66)$. $\mathrm{O}$ resultado indica que a variável Eficiência operacional foi considerada o maior benefício relativo à gestão de processos $(\mathrm{M}=4,19, \mathrm{sd}=0,71)$. Em segundo lugar, verificou-se o foco no cliente como segundo maior benefício proveniente da gestão de processos $(\mathrm{M}=4,08$, $\mathrm{sd}=$ 0,78). A melhoria no desempenho individual $(M=4,03)$ e o fluxo adequado de informações $(\mathrm{M}=4,02)$, apesar de encontrarem-se nas últimas colocações entre os benefícios da gestão de processos, também tiveram média superior a 4,00, verificando que há alta concordância de o uso dos manuais de procedimentos oferece benefícios ao serviço público em todas as suas variáveis. A Tabela 1 apresenta a média e desvio padrão dos benefícios percebidos pela gestão dos processos de trabalho por indivíduos que já utilizaram os manuais de procedimentos de suas unidades de trabalho.

Tabela 1 Média e desvio-padrão dos benefícios percebidos pela gestão de processos de trabalho

\begin{tabular}{lcc}
\hline Variável & Média & Desvio-padrão \\
\hline Geral & 4,08 & 0,66 \\
Eficiência operacional & 4,19 & 0,71 \\
Foco no cliente & 4,08 & 0,76 \\
Melhoria no desempenho individual & 4,03 & 0,66 \\
Fluxo adequado de informações & 4,02 & 0,78 \\
\hline
\end{tabular}

Fonte: Dados da pesquisa.

Tendo em vista que todas as médias foram superiores à 4,00, indicando alta concordância na percepção de benefícios percebidos pela gestão de processos de trabalho, a hipótese 1 foi confirmada.

Apesar da variável Eficiência operacional possuir o maior nível de concordância, o item que apresentou maior relevância entre os respondentes faz parte da subcategoria Melhoria no desempenho individual. Trata-se da percepção de que, com o uso dos manuais, o servidor contribui positivamente para os resultados da organização $(M=4,43)$, apresentando 
também a maior convergência $(\mathrm{sd}=0,80)$. Na mesma categoria, encontrou-se o item que possuiu menor concordância e convergência, que trata do sentimento que o trabalho realizado é reconhecido $(\mathrm{M}=3,55, \mathrm{sd}=1,10)$. O item contribui para que a média dessa variável tenha obtido posição inferior à Eficiência operacional e Foco no cliente. A Tabela 2 apresenta a média e desvio-padrão dos benefícios apresentados no questionário.

Tabela 2 Média e desvio-padrão dos benefícios apresentados no questionário

\begin{tabular}{|c|c|c|c|}
\hline Item & Variável & Média & Desvio-padrão \\
\hline $\begin{array}{l}\text { Percebo que contribuo positivamente para } \\
\text { os resultados da organização. }\end{array}$ & Melhoria do desempenho individual & 4,43 & 0,80 \\
\hline $\begin{array}{l}\text { Compreendo como funciona meu trabalho, } \\
\text { na teoria e na prática. }\end{array}$ & Eficiência operacional & 4,30 & 0,80 \\
\hline $\begin{array}{l}\text { Posso aumentar a satisfação dos meus } \\
\text { clientes. }\end{array}$ & Foco no cliente & 4,25 & 0,73 \\
\hline Posso aumentar minha produtividade. & Melhoria do desempenho individual & 4,21 & 0,84 \\
\hline $\begin{array}{l}\text { Consigo reduzir a possibilidade de erros nas } \\
\text { atividades que realizo. }\end{array}$ & Eficiência operacional & 4,21 & 0,86 \\
\hline $\begin{array}{l}\text { Percebo com clareza as exigências do meu } \\
\text { ambiente de trabalho. }\end{array}$ & Eficiência operacional & 4,17 & 0,85 \\
\hline $\begin{array}{l}\text { Tenho mais segurança sobre meus papéis e } \\
\text { responsabilidades no trabalho. }\end{array}$ & Fluxo adequado de informações & 4,15 & 1,01 \\
\hline $\begin{array}{l}\text { Consigo compreender melhor o processo } \\
\text { como um todo. }\end{array}$ & Fluxo adequado de informações & 4,09 & 1,02 \\
\hline $\begin{array}{l}\text { Consigo utilizar apropriadamente as } \\
\text { ferramentas de trabalho. }\end{array}$ & Eficiência operacional & 4,09 & 0,90 \\
\hline $\begin{array}{l}\text { Posso realizar os processos com maior } \\
\text { qualidade e agilidade. }\end{array}$ & Foco no cliente & 4,06 & 0,97 \\
\hline Consigo padronizar minhas atividades. & Melhoria do desempenho individual & 4,04 & 1,04 \\
\hline $\begin{array}{l}\text { Percebo com clareza quem é o responsável } \\
\text { por cada atividade. }\end{array}$ & Fluxo adequado de informações & 3,94 & 0,99 \\
\hline Consigo dar respostas com maior agilidade. & Foco no cliente & 3,94 & 0,95 \\
\hline Consigo simplificar meu trabalho. & Melhoria do desempenho individual & 3,91 & 0,90 \\
\hline $\begin{array}{l}\text { Percebo melhorias no fluxo de informações } \\
\text { da organização. }\end{array}$ & Fluxo adequado de informações & 3,89 & 0,87 \\
\hline $\begin{array}{l}\text { Sinto que o trabalho que realizo é } \\
\text { reconhecido. }\end{array}$ & Melhoria do desempenho individual & 3,55 & 1,10 \\
\hline
\end{tabular}

Fonte: Dados da pesquisa.

A fim de observar diferenças entre os benefícios percebidos pela gestão de processos entre os diferentes perfis de respondentes, procedeu-se o tratamento de dados, realizando análise através dos dados demográficos, iniciando-se pelo sexo, apresentado na Tabela 3. 
Tabela 3 Média e desvio-padrão dos benefícios percebidos pela gestão de processos de trabalho por sexo

\begin{tabular}{lrrrrrrrrr}
\hline & \multicolumn{2}{c}{ Foco no cliente } & \multicolumn{2}{c}{$\begin{array}{c}\text { Eficiência } \\
\text { operacional }\end{array}$} & \multicolumn{2}{c}{$\begin{array}{c}\text { Melhoria do } \\
\text { desempenho } \\
\text { individual }\end{array}$} & \multicolumn{2}{c}{$\begin{array}{c}\text { Fluxo adequado de } \\
\text { informações }\end{array}$} \\
\cline { 2 - 10 } & Média & SD & Média & SD & Média & SD & Média & SD \\
\hline Geral & 4,08 & 0,76 & 4,19 & 0,71 & 4,03 & 0,66 & 4,02 & 0,78 \\
Feminino & 3,95 & 0,80 & 4,10 & 0,74 & 3,94 & 0,70 & 3,85 & 0,80 \\
Masculino & 4,32 & 0,65 & 4,37 & 0,65 & 4,19 & 0,56 & 4,32 & 0,64 \\
\hline
\end{tabular}

Fonte: Dados da pesquisa.

Verifica-se que os benefícios percebidos não se diferenciam da média geral se relacionados ao sexo dos indivíduos. Nota-se que os homens possuem maior percepção positiva acerca dos benefícios da gestão de processos, obtendo níveis de concordância maiores que 4 em todos os fatores. As mulheres também possuem nível de concordância elevado, porém superior a 4 apenas na variável Eficiência operacional $(4,10)$. Há diferença entre a variável que se percebe menor benefício, sendo o fluxo de adequado de informações para as mulheres $(\mathrm{M}=3,85)$ e Melhoria do desempenho individual para os homens $(\mathrm{M}=$ 4,19). Algumas variações nos benefícios percebidos estão relacionadas à faixa etária, conforme a Tabela 4.

Tabela 4 Média e desvio-padrão dos benefícios percebidos pela gestão de processos de trabalho por faixa etária

\begin{tabular}{lrrrrrrrr}
\hline & \multicolumn{2}{c}{ Foco no cliente } & \multicolumn{2}{c}{$\begin{array}{c}\text { Eficiência } \\
\text { operacional }\end{array}$} & \multicolumn{2}{c}{$\begin{array}{c}\text { Melhoria do } \\
\text { desempenho } \\
\text { individual }\end{array}$} & \multicolumn{2}{c}{$\begin{array}{c}\text { Fluxo adequado de } \\
\text { informações }\end{array}$} \\
\cline { 2 - 10 } & Média & SD & Média & SD & Média & SD & Média & SD \\
\hline Geral & 4,08 & 0,76 & 4,19 & 0,71 & 4,03 & 0,66 & 4,02 & 0,78 \\
Até 30 anos & 3,98 & 0,70 & 4,20 & 0,56 & 3,82 & 0,56 & 3,88 & 0,73 \\
Entre 31 e 49 anos & 4,00 & 0,85 & 4,04 & 0,87 & 4,08 & 0,73 & 3,95 & 0,86 \\
50 anos ou acima & 4,52 & 0,58 & 4,56 & 0,51 & 4,38 & 0,55 & 4,53 & 0,44 \\
\hline
\end{tabular}

Fonte: Dados da pesquisa.

Em relação à faixa etária, verifica-se que os servidores entre 31 e 49 anos percebem os benefícios da gestão de processos de forma diferente da média geral, apresentando a Melhoria do desempenho individual a variável com maior média $(\mathrm{M}=4,08)$. Os indivíduos mais jovens acompanham o padrão geral. Os servidores com idade superior a 50 anos, diferem na média geral no segundo nível de importância em relação aos benefícios, sendo para estes o fluxo adequado de informações ligeiramente mais importante que o foco no cliente. 
O item com maior nível de concordância em relação aos benefícios percebidos pela gestão de processos, os mais jovens têm a compreensão de como funciona seu trabalho, na teoria e na prática, seguido da percepção de contribuição positiva para os resultados da organização. Os indivíduos com idade entre 31 e 49 também tem a percepção de contribuição positiva entre os itens mais valorizados, sendo seguido pelo aumento da satisfação dos clientes. Para os mais velhos, o mais importante é ter segurança sobre seus papéis e responsabilidades no trabalho, perceber com clareza as exigências do ambiente de trabalho e compreender o processo como um todo.

Analisou-se ainda a percepção dos benefícios da gestão de processos em relação à escolaridade dos respondentes. Tendo em vista haver apenas dois respondentes com nível médio e um respondente com doutorado, preferiu-se dividir o grupo em dois níveis: Graduação (incluindo ensino médio e graduação) e Pós-graduação (incluindo mestrado e doutorado). A Tabela 5 apresenta os dados relativos à essa variável.

Tabela 5 Média e desvio-padrão dos benefícios percebidos pela gestão de processos de trabalho por escolaridade

\begin{tabular}{lcccccccc}
\hline & Foco no cliente & \multicolumn{2}{c}{$\begin{array}{c}\text { Eficiência } \\
\text { operacional }\end{array}$} & \multicolumn{2}{c}{$\begin{array}{c}\text { Melhoria do } \\
\text { desempenho } \\
\text { individual }\end{array}$} & \multicolumn{2}{c}{$\begin{array}{c}\text { Fluxo adequado de } \\
\text { informações }\end{array}$} \\
\cline { 2 - 10 } & Média & SD & Média & SD & Média & SD & Média & SD \\
\hline Geral & 4,08 & 0,76 & 4,19 & 0,71 & 4,03 & 0,66 & 4,02 & 0,78 \\
Graduação & 4,06 & 0,79 & 4,14 & 0,76 & 4,06 & 0,70 & 4,03 & 0,76 \\
Pós-Graduação & 4,13 & 0,72 & 4,32 & 0,58 & 3,95 & 0,56 & 3,98 & 0,85 \\
\hline
\end{tabular}

Fonte: Dados da pesquisa.

Tanto os servidores que possuem ensino médio ou graduação como última titulação completa, como os que possuem pós-graduação não se diferenciam da média geral. Apenas a variável fluxo adequado de informações $(\mathrm{M}=3,98)$ é percebida como um benefício ligeiramente superior em relação à melhoria do desempenho individual $(M=95)$. Logo, não se configuram diferenças significativas em relação à escolaridade dos respondentes.

A Tabela 6 apresenta a relação entre o tempo de serviço e os benefícios percebidos pela gestão de processos. 
Tabela 6 Média e desvio-padrão dos benefícios percebidos pela gestão de processos de trabalho por tempo de serviço

\begin{tabular}{lrrrrrrrrr}
\hline & \multicolumn{2}{c}{ Foco no cliente } & \multicolumn{2}{c}{$\begin{array}{c}\text { Eficiência } \\
\text { operacional }\end{array}$} & \multicolumn{2}{c}{$\begin{array}{c}\text { Melhoria do } \\
\text { desempenho } \\
\text { individual }\end{array}$} & \multicolumn{2}{c}{$\begin{array}{c}\text { Fluxo adequado de } \\
\text { informações }\end{array}$} \\
\cline { 2 - 10 } & Média & SD & Média & SD & Média & SD & Média & SD \\
\hline Geral & 4,08 & 0,76 & 4,19 & 0,71 & 4,03 & 0,66 & 4,02 & 0,78 \\
Mais de 10 anos & 4,53 & 0,52 & 4,56 & 0,47 & 4,33 & 0,51 & 4,54 & 0,44 \\
Entre 3 e 10 anos & 3,96 & 0,74 & 4,22 & 0,53 & 4,00 & 0,54 & 4,00 & 0,53 \\
Menos de 3 anos & 3,94 & 0,83 & 3,97 & 0,88 & 3,88 & 0,78 & 3,75 & 0,96 \\
\hline
\end{tabular}

Fonte: Dados da pesquisa.

Verifica-se que os servidores com mais tempo de serviço possuem uma percepção mais positiva em relação aos benefícios da gestão de processos em comparação aos demais. Foi verificada ainda forte convergência entre as respostas dos veteranos. Apesar de verificarem benefícios positivos, os servidores em estágio probatório parecem mais céticos em relação à gestão de processos que os demais.

A hipótese 2 afirmava que as barreiras existentes na gestão de processos dificultam o uso dos manuais de procedimentos pelos servidores da instituição. A fim de verificar se os resultados da pesquisa corroboram com essa hipótese, a Tabela 7 apresenta os itens que representam as principais barreiras para a gestão de processos de trabalho percebidas pelos respondentes.

Tabela 7 Média e desvio-padrão das barreiras para a gestão de processos de trabalho

\begin{tabular}{lcc}
\hline \multicolumn{1}{c}{ Item } & Média & $\begin{array}{c}\text { Desvio- } \\
\text { padrão }\end{array}$ \\
\hline $\begin{array}{l}\text { A burocracia e a cultura da organização dificultam a melhoria dos } \\
\text { processos. }\end{array}$ & 4,24 & 1,18 \\
$\begin{array}{l}\text { Não confio nas atividades de gestão de processos, pois vários projetos } \\
\text { de melhorias já foram realizados no passado e não trouxeram nenhum } \\
\text { benefício. }\end{array}$ & 3,59 & 1,23 \\
$\begin{array}{l}\text { A legislação dificulta que sejam feitas melhorias no processo de } \\
\text { trabalho }\end{array}$ & 3,33 & 1,22 \\
$\begin{array}{l}\text { Sempre que muda a chefia, as prioridades do setor mudam e a gestão de } \\
\text { processos é deixada de lado. }\end{array}$ & 3,28 & 1,29 \\
$\begin{array}{l}\text { Quando um servidor muda de setor, ele leva consigo todas as } \\
\text { informações e fica difícil aprender as atividades. }\end{array}$ & 3,06 & 1,41 \\
\hline
\end{tabular}

Fonte: Dados da pesquisa.

A média geral em relação à existência de barreiras que dificultam a gestão de processos, teve um nível de concordância relativamente baixo, ainda que positivo $(\mathrm{M}=3,50$, 
sd $=0,59)$. Em relação as barreiras para a gestão de processos, verifica-se que a maior delas é a burocracia e cultura da organização, que dificultam a melhoria dos processos. Percebe-se ainda que não houve discordância a respeito de nenhum dos fatores questionados, porém o nível de concordância dos outros quatro fatores foi muito baixo, demonstrando que os servidores são indiferentes quando às barreiras à gestão de processos na Instituição Federal de Ensino Superior estudada.

Dessa forma, a hipótese 2 foi rejeitada, pois não há como afirmar que as barreiras apresentadas na pesquisa se configuram como dificuldade para a gestão de processos na Universidade. No entanto, é importante salientar que a burocracia representa o fator de maior dificuldade para a gestão de processos, corroborando com a literatura tratada no referencial teórico desta pesquisa.

Não houve grandes diferenças entre as variáveis demográficas com relação as barreiras apresentadas no índice geral. Notou-se apenas que os servidores mais velhos $(\mathrm{M}=$ 77) e com mais tempo de serviço $(M=3,76)$, apresentam maior concordância da existência de barreiras que dificultam a gestão de processos.

A hipótese 3 afirmava que com as informações e ferramentas adequadas, os servidores passam a utilizar mais os manuais de procedimentos, melhorando a gestão de processos. Em relação aos dados gerais, verificou-se uma alta concordância em relação aos fatores positivos $(\mathrm{M}=4,56)$ assim como uma forte convergência entre os respondentes $(\mathrm{sd}=0,42)$. A Tabela 8 apresenta os itens que compuseram os facilitadores para a gestão de processos de trabalho.

Tabela 8 Média e desvio-padrão dos facilitadores para a gestão de processos de trabalho

\begin{tabular}{lcc}
\hline \multicolumn{1}{c}{ Item } & Média & Desvio-padrão \\
\hline $\begin{array}{l}\text { Podemos aprender com a experiência de outras instituições para melhorar } \\
\text { a gestão de processos da nossa organização. }\end{array}$ & 4,83 & 0,44 \\
$\begin{array}{l}\text { Acredito que o uso de sistemas de informação possa melhorar a gestão } \\
\text { dos processos da organização. }\end{array}$ & 4,81 & 0,49 \\
$\begin{array}{l}\text { Acredito que a gestão de processos pode vir a ter sucesso caso seja } \\
\text { realizada por servidores, ao invés de empresas de consultoria. }\end{array}$ & 4,03 & 0,91 \\
\hline
\end{tabular}

Fonte: Dados da pesquisa.

Os resultados apresentados corroboram com a afirmação apresentada pela hipótese 3 , sendo então confirmada pela pesquisa. Os itens relativos aos facilitadores da gestão de processos obtiveram um alto nível de concordância e convergência. A aprendizagem com outras instituições foi o item que encontrou maior concordância. $\mathrm{O}$ segundo facilitador com 
maior concordância foi o uso de sistemas de informação, com concordância e convergência semelhantes ao primeiro item. Ainda que o facilitador que afirma que a gestão de processos pode ter mais sucesso caso seja realizada por servidores ao invés de empresas de consultoria tenha o menor índice de concordância, ainda assim foi muito valorizado, com pontuação superior a 4,00. Dessa forma, verifica-se alto grau de concordância entre todos os fatores que podem vir a facilitar a gestão de processos de trabalho no serviço público.

Não foi verificada nenhuma diferença significativa entre os facilitadores apresentados e as variáveis demográficas da pesquisa.

\section{CONSIDERAÇÕES FINAIS}

A proposta do trabalho foi analisar os fatores que interferem na gestão de processos de trabalho em uma Instituição Federal de Ensino Superior, partindo das hipóteses que o uso dos manuais de procedimentos garante melhor desempenho e eficiência no trabalho realizado, com foco no cliente; as barreiras existentes na gestão de processos dificultam o uso dos manuais de procedimentos pelos servidores da instituição; e que, com as informações e ferramentas adequadas, os servidores passam a utilizar mais os manuais de procedimentos, melhorando a gestão de processos.

Os resultados confirmaram as hipóteses 1 e 3, uma vez que foi verificado alto índice de concordância relativo aos benefícios e facilitadores à gestão de processos de trabalho na Universidade pesquisada. A hipótese 2 foi rejeitada, tendo em vista que os servidores aparentam ser indiferentes quando às barreiras para a gestão de processos apresentadas.

Recordando os objetivos específicos da pesquisa, em relação ao objetivo específico 1 , que pretendia analisar os benefícios percebidos pela gestão de processos de trabalho, verificou-se uma alta concordância acerca da existência de benefícios no serviço público em relação à gestão de processos e o uso dos manuais de procedimento. O resultado indicou que a variável Eficiência operacional foi considerada o maior benefício relativo à gestão de processos, seguida do foco no cliente, melhoria do desempenho individual e fluxo adequado de informações, respectivamente.

Em relação ao objetivo específico 2, que pretendia analisar as barreiras para a gestão de processos de trabalho, foi verificado que os servidores são indiferentes quando às dificuldades impostas pelas mesmas. No entanto, é importante salientar que a burocracia representa o fator de maior dificuldade para a gestão de processos, o que corrobora e justifica 
às várias ações do governo no sentido de desburocratizar a máquina pública, visto que este é o principal gargalo apresentado na literatura e também foi verificado nos resultados desta pesquisa.

Em relação ao objetivo específico 3, que pretendia analisar os facilitadores para a gestão de processos de trabalho, verificou-se que itens relativos aos facilitadores da gestão de processos obtiveram um alto nível de concordância e convergência. A aprendizagem com outras instituições foi o item que encontrou maior concordância. Não foi pesquisado se tal comportamento é colocado em prática, mas é um achado importante identificar que os servidores públicos estão interessados em realizar o networking como ferramenta de gestão.

Além disso, tendo em vista que o segundo facilitador com maior concordância foi o uso de sistemas de informação, acredita-se que seja interessante a criação, se é que já não existe, de uma plataforma virtual que possa facilitar a troca de informações quanto à padronização dos processos de trabalho intra e entre Universidades.

De modo geral, verifica-se que a gestão de processos de trabalho é vista como uma intervenção positiva na administração pública e que há receptividade dos servidores para que esse método de trabalho seja aplicado a fim de que a desburocratização possa tornar-se a rotina da gestão governamental, atendendo de forma satisfatória os clientes internos e externos das instituições.

É importante salientar que os resultados aqui apresentados não podem ser tomados como representativos no universo do serviço público ou ainda das Instituições Federais de Ensino Superior, categoria extremamente ampla e não abrangida pelos métodos de amostragem utilizados na pesquisa.

Como sugestões para investigações futuras, sugere-se um estudo utilizando uma amostra mais representativa, assim como a realização de pesquisa em instituições em que a gestão por processos já esteja implementada no âmbito de toda a organização. Sugere-se ainda a realização de estudos empíricos em outros setores de trabalho, além das IFES, com vista à identificação de similaridades e diferenças entre os diversos órgãos públicos.

\section{REFERÊNCIAS}

AALST, W. M. P. van der; HOFSTEDE, A. H. M.; WESKE, M. Business Process Management: A Survey. Lecture Notes in Computer Science. p. 1-12. 2003.

ASSOCIATION OF BUSINESS PROCESS MANAGEMENT PROFESSIONALS. Guia para o gerenciamento de processos de negócio corpo comum de conhecimento. ABPMP 
BPM CBOK v.3. 2013. Disponível em

$<$ http://c.ymcdn.com/sites/www.abpmp.org/resource/resmgr/Docs/ABPMP_CBOK_Guide Portuguese.pdf $>$ Acesso em 09 de maio de 2016.

BENEDICTIS, C. C. de.; AMARAL, D. C.; ROZENFELD, H. Evaluation of the main existing methods and tools for product development process modeling. Product: Management \& Develpment. v. 2, n. 2, p. 19-27. mar. 2004.

BRASIL. Decreto n ${ }^{0} 7.232$, de 19 de julho de 2010. Dispõe sobre os quantitativos de lotação dos cargos dos níveis de classificação "C", "D" e "E" integrantes do Plano de Carreira dos Cargos Técnico-Administrativos em Educação, de que trata a Lei no 11.091, de 12 de janeiro de 2005, das universidades federais vinculadas ao Ministério da Educação, e dá outras providências. Disponível em <http://planalto.gov.br>. Acesso em 18 de junho de 2016.

CAPUANO, E. A. Construtos para modelagem de organizações fundamentadas na informação e no conhecimento no serviço público brasileiro. Ciência da Informação. Brasília, v. 37, n. 3, p. 18-37, set./dez. 2008.

COELHO, E. M. Governo eletrônico e seus impactos na estrutura e na forca de trabalho das organizações públicas. Revista do Serviço Público. v. 52, n. 2 abr./jun. 2001.

COLLIS, J.; HUSSEY, R. Pesquisa em administração: um guia prático para alunos de graduação e pós-graduação. 2 ed. Porto Alegre: Bookman, 2005.

CRESWELL, J. W. Projeto de pesquisa: métodos qualitativo e quantitativo. 3 ed., Porto Alegre: Artmed, 2010.

DANTAS, A. S.; QUEIROZ, F. C. B. P.; QUEIROZ, J. V. Gestão de processos e avaliação de desempenho no setor público brasileiro: um estudo de caso em uma instituição de ensino superior pública. In: X Coloquio Internacional sobre Gestión Universitaria en América del Sur. Anais... Mar del Plata: X SIGU, 2010.

GONÇALVES, J. E. L. As empresas são grandes coleções de processos. Revista de Administração de Empresas (RAE). São Paulo. v. 40 n. 1. P. 6-19. jan./mar. 2000.

GONÇALVES, G. A. C.; MEDEIROS JUNIOR, G.; DE MORAIS, L. C. M.; MARTINS, P. E. M.; DE SOUSA, S. M. A. O papel social do administrador: Formação e Perspectivas à luz da administração pública. IV Encontro de Administração Pública. Vitória da Conquista, BA, 2013.

HOMBURG, V. E-government and NPM: a perfect marriage?. In: JANSSEN, M.; SOL, H. G.; WAGENAAR, R. (Ed.). ICEC'04 - International Conference on Electronic Commerce. 6., 2004. Anais... Association for Computing Machinery, 2004.

LIZARELLI, F. L.; MADIOLO, A. de S.; MARTINS, M. F.; MORISHITA, C. S.; ITO, M. A. O. Gestão de processos em uma empresa do setor elétrico. Revista de Gestão da Produção - GEPROS. Ano 1. ed. 2. abr. 2006. 
LORENA, A. L. F. de.A contribuição estratégica da ouvidoria pública para a gestão de processos de negócios na IFES. In: XV Colóquio Internacional de Gestão Universitária CIGU, 2015. Anais... Mar del Plata: XV CIGU, 2015.

LUO, W.; TUNG, Y. A. A framework for selecting business process modeling methods. Industrial Management \& Data Systems. v. 99 n. 7. p. 312-319. 1999.

MAY, T. Pesquisa social: questões, métodos e processo. Tradução Carlos Alberto Silveira Netto Soares. 3. ed., Porto Alegre: Artmed, 2004.

MELÃO, N.; PIDD, M. A conceptual framework for understanding business processes and business process modelling. Info Systems Journal. v. 10. p. 105-129. 2000.

MINISTÉRIO DO PLANEJAMENTO, ORÇAMENTO E GESTÃO. Guia D Simplificação. Brasília: MPOG/SEGES, 2006. Disponível em:

$<$ http://indicadores.fecam.org.br/uploads/28/arquivos/4107_MINPLANEJAMENTO_Gespubl ica_Guia_de_Simplificacao_de_Processos.pdf> Acesso em 24.05.2016.

MINISTÉRIO DO PLANEJAMENTO, ORÇAMENTO E GESTÃO. Guia de Gestão de Processos do Governo. 2011. Disponível em:

$<$ http://gestao.planejamento.gov.br/gespublica/sites/default/files/documentos/guia_de_gestao_ de_processos_de_governo_0.pdf> Acesso em 09 de maio de 2016.

MINISTÉRIO PÚBLICO FEDERAL. PROCURADORIA GERAL DA REPÚBLICA. Manual de gestão por processos: Secretaria Jurídica e de Documentação. Escritório de Gestão de Processos Organizacionais do MPF. Brasília: MPF/PGR, 2013.

MÜCKENBERGER, E.; TOGASHI, G. B.; PÁDUA. S. I. D.; MIURA, I. K. Gestão de processos aplicada à realização de convênios internacionais bilaterais em uma instituição de ensino superior pública brasileira. Produção. v. 23, n. 3, p. 637-651, jul./set., 2013.

OLIVEIRA, D. P. R. Sistemas, organização e métodos: uma abordagem gerencial. 15 ed. São Paulo: Atlas, 2005.

OLIVEIRA, R. A. de; KAMIMURA; Q. P.; TADEUCCI, M. de S. R. Limites encontrados na gestão pública federal: o caso do campus universitário de Gurupi - UFT. In: VII Congresso Nacional de Excelência em Gestão, 2011. Anais... Rio de Janeiro: VII CNEG, 2011.

OLIVEIRA NETO, A. A utilização de manuais administrativos como ferramentas indispensáveis à gestão pública. Disponível em:

$<$ www.administradores.com.br\%2Fproducao-academica $\% 2 \mathrm{Fa}$-utilizacao-de-manuaisadministrativos-como-ferramentas-indispensaveis-a-gestao-publica> Acesso em 18 de junho de 2016.

PAIM, R.; CARDOSO, V.; CAULLIRAUX, H.; CLEMENTE, R. Gestão de processos: pensar, agir e aprender. Porto Alegre, Bookman: 2009. 
ROSEMANN, M.; MACIEIRA, A.; KARRER, D.; JESUS, L. Um framework para operação do escritório de processos. Elo Group, 2009.

SANTOS, H. M.; SANTANA, A. F.; ALVES, C. F. Análise de fatores críticos de sucesso da gestão de processo de negócio em organizações públicas. Revista Eletrônica de Sistemas de Informação. v. 11, n. 1, jan-jun, art. 3, 2012.

SILVA, R. S.; PERIOTTO, A. J. Políticas de investimentos em tecnologia e a gestão da informação no setor público municipal: o caso da prefeitura de Campo Mourão - PR. In: I Encontro de Administração da Informação, 2007. Anais... Florianópolis: I ENADI, 2007.

TAIT, T. F. C. Um modelo de arquitetura de sistemas de informação para o setor público: estudo em empresas estatais prestadoras de serviço de informática. Tese (doutorado). Florianópolis: UFSC, 2000.

UNIVERSIDADE FEDERAL DO CEARÁ. Plano de desenvolvimento institucional - PDI 2013-2017. Fortaleza, 2012. 173p. 